\title{
Parents in child custody disputes: Why are they disputing?
}

\section{Ann-Sofie Bergman \& Annika Rejmer}

To cite this article: Ann-Sofie Bergman \& Annika Rejmer (2017): Parents in child custody disputes:

Why are they disputing?, Journal of Child Custody, DOI: $10.1080 / 15379418.2017 .1365320$

To link to this article: http://dx.doi.org/10.1080/15379418.2017.1365320

曲 Published online: 19 Sep 2017.

Submit your article to this journal ๔

Џ Article views: 123

Q View related articles $\square$

View Crossmark data ¿ 


\title{
Parents in child custody disputes: Why are they disputing?
}

\author{
Ann-Sofie Bergman ${ }^{a}$ and Annika Rejmer \\ aDepartment of Social Work, Linnaeus University, Växjö, Sweden; bFaculty of Law, Uppsala University, \\ Uppsala, Sweden
}

\begin{abstract}
Since 2000, the number of custody disputes has increased in Sweden. Living in the midst of a parental conflict places the children under great stress. Research on parental conflicts is predominantly theoretical; thus, there is a need for empirical studies to better understand the problems and needs of the children and parents. This article examines parental disputes regarding custody, residence, and access for children, and aims to understand the characteristics of the conflicts behind the disputes. The article is primarily based on qualitative analyses of court documents. The results show that the majority of the parents' conflicts are defined as conflicts of values, stemming from concern about the other parent's capability to care for younger children.
\end{abstract}

\section{KEYWORDS}

Child custody; conflicts of interest; conflicts of values; divorce; family life-trajectory; gender; high-conflict divorce; parenting issues

\section{Introduction}

In Sweden, the social phenomenon of custody disputes can be dated back to the latter half of the 1970s, when family norms changed and the number of divorces rose. One explanation for the rise comes from a change in the law that made it easier to divorce. If the partners were in agreement and did not have any children under the age of 16 , they no longer needed to undergo the period for consideration. If younger children were concerned, a six-month period for consideration was introduced, in contrast to the previous minimum of a one-year judicial separation. One other explanation for the rise in divorces during the second half of the previous century is the expanding welfare state. The Swedish welfare model has, to a great extent, been tied to the individual, subsequently making adults less dependent upon family connections for their social and financial security. The expansion of the welfare state has resulted in reduced obstacles for divorce, especially for women and people on a low income (Sandström, 2012).

Between 2000 and 2010, nearly 50,000 Swedish children each year experienced a parental separation (Statistics Sweden, 2013). This means that each year approximately $3 \%$ of children (aged $0-17$ ) have parents who part ways. Separations most commonly occur when the children are between 
one and four years old. In 2011, one in three children born in Sweden had gone through a parental separation by the age of 17 . One group of children that has increased over time consists of children who have never lived together with both parents. In some cases, the parents have separated before the child's birth; in others, they have never lived together (Statistics Sweden, 2013).

Even if the number of children affected by a family breakup has been fairly consistent since 2000, there has been an increase in the number of conflicts regarding custody, residence, and access (Swedish National Courts Administration, 2003, 2009, 2013). More parents are taking legal action against each other in the courts. Official statistics show an increase of approximately 60\% in custody cases between 2000 and 2013 (Swedish National Courts Administration, 2003, 2009, 2013). Great strain is placed upon children living amid serious parental conflict. These children are at increased risk of psychiatric, behavioral, and school-related problems (Kelly \& Emery, 2003; Leon, 2003). Long-term custody battles can lead to mental health problems for the children, even after they have become adults (Johnston, Roseby, \& Kuehnle, 2009; Stewart, 2000). Helping parents involved in a custody dispute poses a great challenge for society as it can require effort and resources (Saini et al., 2012). This study explores parental disputes regarding custody, residence, and access with joint children. The aim is to understand the characteristics of these conflicts that form the basis of parental disputes. This study focuses on the questions: Based on the concepts of "conflict of values" and "conflict of interest," what are the characteristics of the parental conflicts? How can the conflicts be understood from the perspectives of life-trajectory and gender?

The subject is relevant for all professionals involved in handling of custody disputes and especially social workers who in their practice are providing courts with rapid information inquiries and custody investigations. Many children who are the focus of a custody dispute are also cases at the social services as child protection investigations because of concerns regarding inadequate care. All professionals need knowledge regarding custody conflicts to better understand problems and be able to provide relevant support.

\section{Theoretical framework}

After a divorce, the majority of parents manage to deal with the feelings of anger, disappointment, and loss, and build healthy relationships, but $20-40 \%$ develop conflicts with each other (Saini \& Birnbaum, 2007). However, not all conflicts lead to court disputes. Many parents may be in conflict with each other at the time of separation, but conflict levels often decrease over time. Nevertheless, for one group of parents, the conflicts continue over a longer period or may even intensify over time (Kelly \& Emery, 
2003). In Sweden, approximately $14 \%$ of children of divorce or separation experience their parents disputing in court about custody, residence, and access (Swedish National Board of Health and Welfare, 2011). Research regarding high-conflict parental conflicts is primarily based on theoretical approaches and requires further empirical studies within the area to help create a better understanding of the problems and needs of children and parents (Birnbaum \& Bala, 2010). To be able to develop relevant support for families involved in custody disputes, a differentiation of the conflicts' characteristics is needed. To analyze parental conflicts, it is possible to differentiate between conflicts regarding finances, division of residence, custody, or time with the children and differences of opinion regarding how to raise the child (Johnston, 1994). The division can also be categorized as conflicts of interest and conflicts of values. It is common for conflicts to include elements of both conflicting interests and values (Rejmer, 2003).

A conflict of values concerns different opinions about both facts and values, whereas a conflict of interest is primarily characterized by parties having opposing demands for a scarce resource (Aubert, 1989). A custody conflict can be categorized as a conflict of interest when the parents disagree on matters relating to time with the child, maintenance responsibilities, or the right to information about the child. A custody conflict can be categorized as a conflict of values when the parents disagree on matters of parental or cooperation capabilities, or due to parents' problems with drugs, mental health, and systematic violence in the home. Conflicts of interest can be solved via mediation and compromises, because the parties tend to not want to risk a total loss. On the other hand, conflicts of values often require the involvement of a third party in order to be settled. This is due to difficulties in mediating on issues concerning parental or cooperative abilities due to drug problems, mental disorders, or violence.

Parental conflicts can be placed into a context of the parents' and children's life-trajectory, which is formed on the notion that a person's life-story and its surrounding context are of significance for their current situation. Separation is a critical life event, a turning point and loss that changes life's trajectory. Compared to anticipated changes, a separation followed by a custody conflict is often a traumatic change and can be regarded as a life crisis. Separation and parental conflicts have different effects on family members, depending upon when in the course of their life it takes place. For families with younger children who are the most vulnerable, separation and a subsequent custody dispute are particularly difficult changes. Conflicts may arise when the normal way of managing situations no longer functions, when many stressors overlap, and when previous crises have not been dealt with (Ahrons, 2011).

Other relevant factors for the analysis of parental disputes include the concepts of gender, which relates to the social behavioral expectations placed on mothers (women) and fathers (men). Gender is created by day-to-day 
interplay and practice that is constantly reproduced, but can also be changed by altering the collective social orders of society (Connell, 1987; Giddens \& Birdsall, 2003). One example is how the quest for gender equality of recent decades has contributed to improved contacts with both parents after a separation. Fathers have become more involved in the care of their children and have begun to play a greater role in their lives (Birnbaum \& Bala, 2010). In Sweden, the number of children who alternate living with their parents after a separation has increased. Currently, around one-third of children whose parents have separated alternately live with their mother and their father. However, the alternating living situation is a solution that is primarily used in conjunction with the parents' separation. As time passes, fewer children alternate their living. It is often the case that children whose parents have separated live with their mother (Statistics Sweden, 2014). Despite the increased participation of fathers in child care, when living apart, parenthood cannot yet be regarded as equal. Separation is believed to contribute to highlighting and strengthening the gender-specific division of work between the parents (cf. Johansson, 2012).

\section{Methods}

The study is a part of the research project "High-Conflict Families of Divorce a study of children in custody conflicts and an effect analysis of three processing models." The empirical data for this study has been collected by a combination of quantitative and qualitative methods. The main study is a total survey consisting of 1,087 summons applications from six district courts in the Stockholm area during three months in 2013. Four hundred and fortythree of them that concern parents disputing custody, residence, or access have been subjected for analysis. This article is based on the results of primarily qualitative content analyses of summons applications, statements of defense, rapid information inquiries, and custody investigations. A total of 44 randomly chosen cases have been investigated (10\% of the total survey material). Of the cases investigated, eleven were excluded as they were judged as being nonstandard custody disputes, not characterized as high conflicts between the involved parents. These cases concerned unaccompanied minors (refugees), children moving from abroad to a parent in Sweden, children whose parents were applying for joint custody during dissolution of marriage, and cases where the summons application was withdrawn after a short period. This means that $75 \%$ of the cases examined included a parental dispute. Analyses of documents from 33 cases have been made accordingly, and include 57 children. The material includes a total of 33 summons applications and 28 statements of defense from parents, 26 rapid information inquiries, and 4 custody investigations from the social services. The custody investigations, which comprise more comprehensive material, concern a total of nine children. 
Quantitative and qualitative analyses may complement each other. While quantitative content analyses can provide a general view and show patterns, qualitative analyses contribute to a visualization of the affected parties' argumentation in conflict situations (cf. Bergström \& Boréus, 2005). This study is primarily based on qualitative analyses. However, we also used quantitative data to provide background information regarding the parents, children, and conflicts. We began our analysis work by thoroughly reading each case and noting the reasons stated by the parents as background to their conflicts. In the next stage, we categorized the conflicts based on the concepts of conflict of interest and conflict of values (Rejmer, 2003). To a great extent, the material is normative in character; the parents express their subjective opinions regarding the conflicts in question. Different voices and perspectives emerge from the material as the parents respond to a summons application with a statement of defense. In many cases, an impartial voice is also present when the social workers comment on the cases. In a number of cases, the child's voice is also heard after the social services have conducted and documented interviews with children. The material has been analyzed in order to create the understanding of the conflict areas and to find recurring patterns in parental conflicts.

The study is ethically vetted by the Regional Ethical Review Board, Lund (ref. 421-2011-1932). The study has been implemented in accordance with current ethical rules. The source material forming the basis of this analysis comes from official public documents that have been ordered from the district courts. To protect the children and parents included, data has been anonymized and presented on a generalized level so that no person can be recognized.

\section{Results}

The following section presents the results. The section begins with a presentation of the children involved. Subsequently, analyses of the conflict areas are presented in addition to in-depth qualitative analyses of conflicts of interest and conflicts of values. Then, the conflicts are analyzed from a life-trajectory and gender perspective.

\section{Children and parents}

The analyses show that it is more common that the disputes involve younger children; two-thirds are under the age of 9. The oldest children, aged 15-17, belong to groups of siblings where the cases also involve younger children. Children are, on average, seven years old at the time when the summons application is submitted to the court. For many children, once the cases reach the district court, a few years have passed since their parents' separation. 
On average, children were four years old when the parents separated. The national statistics show that the greatest risk of parents separating comes when the children are aged between one and four years (Statistics Sweden, 2013).

The largest proportion of children affected by the conflicts have parents who hold joint legal custody (93\%), while for $7 \%$ of the children the mother is the sole legal custodian. This finding complies with the national statistics of child custody in Sweden (Statistics Sweden, 2014). The majority of divorced parents hold joint custody. In the case where one parent is sole custodian, it is more likely to be the mother than the father. In terms of physical care and residence, however, a high percentage of the children in the study live with their mothers (75\%), while $12 \%$ live with their fathers and $12 \%$ alternate their residence on a weekly basis between parents. Children who live with their mother are generally younger than those living with their father. The children who alternate between their parents are the youngest. The public statistics show that alternating residence is more common when the parents have recently separated (Statistics Sweden, 2014). The fact that children have residence with one of their parents does not indicate that they have no contact with the other parent. Most children in Sweden have contact with both parents after a separation (Statistics Sweden, 2001).

\section{Custody, residence, and access}

The majority of cases deal with custody of the child (88\%), followed by residence $(67 \%)$, and access $(58 \%)$. An analysis from a gender perspective shows that there are differences between what the mothers and fathers request in the summons applications (see Table 1). More mothers than fathers request

Table 1. Requests and replies to requests from mothers and fathers ${ }^{a}$.

\begin{tabular}{lcc}
\hline Requests & Mothers & Fathers \\
\hline Custody & 22 & 7 \\
Request for sole custody & 5 & 13 \\
Reply to request: Contests sole custody with the other parent & 2 & 10 \\
Request for joint custody & 1 & - \\
Reply to request: Contests joint custody & 14 & 11 \\
Residence & 5 & 5 \\
Request for permanent residence & 1 & 1 \\
Reply to request: Contests permanent residence with the other parent & 2 & 11 \\
Reply to request: Consents to permanent residence with the other parent & 2 & 1 \\
Request for alternating residence & 3 & 13 \\
Reply to request: Contests alternating residence & 3 & - \\
Access & - & 1 \\
Request for the child's right of access with the requesting parent & 2 & - \\
Request for the child to have supervised contact with the other parent & 3 & 1 \\
Request for the child to have supervised contact with the requesting parent & & \\
Request to regulate the child's access with the other parent & & \\
Reply to request: Contests the child's access with the other parent & & \\
\hline
\end{tabular}

according to summonses application and statements of defense. 
sole custody; whereas, more fathers request joint custody. The cases regarding residence primarily involve one parent requesting for the children to live with them permanently. Many parents state that they want the children's alternating residence situation to cease as the set-up has not worked. However, there are also parents-more fathers than mothers-who request for alternating residence for the children. Cases regarding access often involve fathers who want increased access to their children. In some access cases, mothers request for regulation of the children's visitation with their father, either that there is no access at all between father and child or that access takes place with supervision. In one case, the father requests for no access to take place between the children and the mother.

\section{Conflict areas}

The analyses of the parental conflicts have been divided into conflicts of values and conflicts of interest. It is obvious that the majority of cases deal with conflicts of values. Out of 33 cases, 31 involve a conflict of values. Thirteen out of 33 cases involve a conflict of interest. One-third of the cases present a combination of conflicting values and interests, that is, an overlap of both conflict types. There were only two cases solely involving a conflict of interest.

Conflicts of interest may involve: division of time spent with the child, the child's residence, finances, and lack of communication/information. The majority of conflicts of interest involve communication and information, access time, and finances (see Table 2). When it comes to conflicts of values, these can be a question of collaboration difficulties, addiction, violence, threats, violations, mental illness, physical illness, lack of child care ability, threat/risk that the child will be taken abroad, sexual assault of children, the child's wishes, or access sabotage. The most common conflict area

Table 2. Parental conflicts divided into conflict areas.

\begin{tabular}{lc}
\hline Conflict areas & Number of cases (\%) \\
\hline Conflicts of interest & $13(39)$ \\
Division of time with the child & $6(18)$ \\
Lack of communication/information & $6(18)$ \\
Finances & $4(12)$ \\
Child's residence & $2(6)$ \\
Conflicts of values & $31(94)$ \\
Lack of child care ability & $27(82)$ \\
Cooperation difficulties & $26(79)$ \\
Violence/threats/abuse & $17(52)$ \\
Addiction & $13(39)$ \\
Child's wishes & $10(30)$ \\
Mental or physical illness & $9(27)$ \\
Access sabotage & $8(24)$ \\
Threat/risk of taking child abroad & $3(9)$ \\
Sexual assault of child & $1(3)$ \\
Total number of cases & $33(100)$ \\
\hline
\end{tabular}


involved a lack of capability to care for the child, followed by cooperation difficulties and then conflicts involving violence/threats/abuse. In Table 2, the state of physical and mental health causing the grounds for conflict have been combined, as interpretations of the problems can differ. One parent can complain that the other has mental health problems, whereas the other may emphasize that they have physical health problems. In certain cases, there is an overlap between a lack of child care capability and cooperation difficulties. This can be as a result of the parents having different opinions about what constitutes good care of their children.

\section{Conflicts of interest}

It is commonplace for conflicts of interest to arise in combination with conflicts of values. Conflict of interest alone is the least common form of conflict. Only two cases have shown that the conflict between the parents solely relates to a conflict of interest. What, then, are these conflicts about? The cases involve custody and access with children. In both these cases, the father was the initiator of the summons application. They request for joint custody of the children. They want an increased opportunity to see their children. These conflicts can be said to be about the division of a resourcetime with children-that the fathers are unhappy with and thus want to see a change. It concerns parents who are in the midst of the separation.

\section{Communication and information}

The most common conflict of interest involves communication/information and time with the children. In some of the cases where communication/ information conflicts exist, the mothers are the ones to instigate the summons applications, as they want sole custody of the child and residence. In these cases, the apparent conflicts are about insufficient information about what takes place when the child is with the other parent, for example information regarding the child's illnesses and visits to the doctor. These cases involve the youngest children, where one parent is dependent on the other for information as the children themselves cannot be expected to provide it. On the other hand, the fathers who mention information and communication-related conflicts convey their wish for joint custody of the children. Fathers protest because they want to participate more in their child's life and in decisions regarding the children. According to Swedish legislation a noncustodian parent has only the right to receive information necessary for access. (Children and Parents Code, Chapter 6, Section 15; Children and Parents Code, Chapter 6, Section 2).

\section{Time with the children}

Conflicts of interest can include the division of time spent with the children. The majority of these cases deal with fathers who want increased access to 
their children; in many of the cases, the mother is the sole custodian. Each case concerns younger children, as young as one or two years old. Most of these parents have separated relatively recently.

\section{Finances}

Financial conflicts involve the division of the child's maintenance; how the child benefit will be distributed and used, and if the child's maintenance allowance has not been paid. Other conflicts involve who will cover the costs related to access, preschool/school, or issues regarding the child's bank account. Conflicts can also concern property division after separation. Both mothers and fathers mention financial conflicts.

\section{Children's residence}

Conflicts of interest can revolve around the children's residence. In two cases, the mothers request for their children to permanently live with them as they believe that alternating residence has not worked for the children. This can, in part, be considered as a conflict of interest when the parents disagree about where the children will live. In two of the cases, however, it is clear that the problem is primarily due to conflicts of values. The parents state that they have "serious cooperation difficulties" and that they are living in the midst of a "long-lasting conflict." Analyses show that, for these cases, the parents have been separated for longer than four years. The children are aged eight to ten and so have lived with the conflict for half of their lives.

\section{Conflicts of values}

A conflict of values is the most common type of conflict between disputing parents. Thirty-one of 33 cases involve conflicts of values.

\section{Lack of child care ability}

The most common conflict is a lack of child care ability. Parents raise the notion that the other one lacks the ability to meet the child's basic needs, such as food, sleep, hygiene, dental care, and routines. In other cases, the lack of child care ability may be due to a lack of supervision. There are examples of younger children being "lost" or going "missing" for several hours. Parents express their worries about what may happen when their children are with the other parent. Other conflicts involving child care relate to the expectations that can be placed on the children based on their age; for example, if it is suitable for the child to look after younger siblings. The treatment of the children can also be included in the child care deficiencies. One parent believes that the other neglects the child and "does not show them respect." Child care problems can also include neglect in the form of absence in cases where it is not possible to contact one parent, making joint custody difficult. 
One mother requests for sole custody in order "to be able to take responsibility for the children's day-to-day care without needing to fight for documents to be signed."

The concerns of inadequate care can be reflected in the frequent reports to social services. In eight cases, reports of concern have been submitted to social services during the dispute period. The social services have open child protection investigations in eight cases, and in a further eight cases investigations have been conducted previously. This means that in 16 of 33 cases, a child protection investigation is conducted due to concerns regarding the children's situation. In eleven of these cases, the children have been investigated by social services more than once. Information regarding insufficient care concerns children of all ages but is more common amongst younger children.

\section{Cooperation difficulties}

Cooperation difficulties form the next most common conflict. Examples of cooperation difficulties raised include disagreements regarding the child's needs, the choice of school, whether the child is to receive treatment from child psychiatry, disagreements regarding the child's free-time and travel, different opinions of what the child can manage, in addition to disagreements due to agreements not being followed. Parents state that it is not possible to make joint decisions for the children. Cooperation difficulties are mentioned by both mothers and fathers. One difficulty raised is that parents mention that they are unable to contact the other to discuss important decisions regarding the children. This often occurs when signatures are required for school/preschool or passport documents.

\section{Violence, threats, and abuse}

Conflicts relating to violence/threats/abuse are often brought up by mothers. In many cases, they deal with violence against the mother. A number of cases mention that the children have witnessed the father's violence against the mother and others name incidents where both mother and child have been subjected to violence from the father. When fathers bring up problems on the theme of violence, they involve violence against the children, or experiencing harassment from the child's mother. The material provides details of physical and psychological violence, abusive treatment, threats or control. These often occur in combination. One mother describes how the children's father has subjected her to threats/violence for many years. The violence can be a reason why the mother has chosen to leave the relationship.

Many parents explain that their children have been subjected to violence. The majority of cases speak about how the other parent has been violent towards the child, although the violence may also come from one of the parents' new partner. According to the parents, the children have been subjected to physical and psychological violence and abusive behavior. In 
many cases, the accounts diverge when the parents deny that they have used violence: "[the father] firmly refutes the accusation [coming from the mother] of threats and violence." However, there is an example of one of the parents telling professionals that they themselves have hit their children. The material provides details of children who tell social services staff that they have seen their father use violence against their mother, as well as information about how they themselves have been subjected to violence. In some cases, the children state that they are afraid of a parent. As a result of the violence against mothers and children, many cases have involved the legal system. The material includes details of police reports regarding suspected violations of integrity, fathers who are in custody or have been convicted of violence, and legal decisions on restraining orders for fathers. In additional cases, the mother and child have moved to protected housing via women's organizations or social services. There are also details of children who have received treatment as a result of being subjected to violence. Conflicts involving violence apply to children of all ages. For the youngest children, it is first and foremost that the child witnesses violence against the mother, whereas the children who state they have been subjected to physical or psychological violence are often somewhat older. In one case, the mother states that her child has been subjected to sexual assault by the father.

\section{Addiction and health problems}

Cases of parents with addiction mostly involve the fathers' addiction, and in a few cases, the mothers' addiction. Generally it is a case of alcohol addiction, but other drugs are mentioned too. Some cases are word-against-word, where one parent claims the other has a problem with addiction and the other denies it. In other cases, the addiction is known and documented by the social services. There are parents who are in contact with addiction units and children who participate in support services for children whose parents are addicts. The children describe these problems in some of the cases. There are children who tell social services staff about their own worries about a parent's "drinking," about problems of "always needing to be on guard," and "never being able to relax" when spending time with the parent.

Health problems mainly involve one of the parents having a mental illness. The majority involve the mothers' mental illness. In some of the cases, investigations by social services also mention the parents' mental illness; this applies to both mothers and fathers. No parent brings up a personal problem with addiction and it is uncommon for parents to bring up their own mental health problems. However, some parents mention that the custody conflict has had a negative impact on their health. In some cases, where addiction and/or mental illness are discussed, a complex picture of problems within several areas is apparent. In addition to addiction and/or mental illness, details of insufficient child care and violence also emerge. 


\section{The children's wishes}

It happens that parents refer to the child's wishes in their argumentation. These children are generally slightly older in comparison with the whole group. More mothers than fathers refer to their understanding of what their child wants. This can be explained through the fact that the majority of children live with their mothers. The parents argue about what the child wants or does not want regarding residence and/or access. In certain cases, the parents differ in their understanding of the child's wishes: "We have different ideas of what [the child] wants." Many children clearly express their wishes in interviews with social services staff. However, some children discuss the difficulties they have expressing their wishes to their parents. This can be due to taking a parent who is not feeling well into consideration, but it can also be down to a fear of the parent's reaction, that the parent will be angry if the child expresses what they want. There are also examples of how it is difficult for the child to express their wishes-or even to know what they want-when the child lives with parents in serious conflict with each other. This shows the importance of the child being made aware that they have the right to make their opinion heard, but that they do not need to talk. It is also apparent that the child may need the opportunity to be heard on several occasions, not simply on one deciding occasion.

\section{Access sabotage}

Conflicts that can be related to access sabotage are mentioned by both mothers and fathers. These conflicts concern the younger children. It can be that one parent is said to "sabotage and not adhere to the agreed times" regarding access, which is said to have led to worry and uncertainty in the children regarding structure and knowing which parent they are supposed to be with at any given time. In other cases, there is information regarding how one parent negatively influences the child's relationship with the other parent either by speaking ill of the parent in front of the children, or by attempting to influence the children so that they do not want to be with the other parent or "become distanced" from the parent. In one case, a parent states that they were unaware of where the children were because "each contact [attempt]" had been "refused" for a long time.

\section{Threat or risk of child being taken abroad}

Finally, the threat/risk that the child will be taken abroad is raised in some cases. Three mothers and one father mention this problem. The parents express their concern that, after the divorce, the other parent will take the children to their "home country" (i.e., the country where the parent was born); hence, the parents are worried that they will lose contact with their children. In two of the three cases, both parents come from different countries. In each of the aforementioned cases, the matters of violence/ 
threats/abuse are mentioned. In one case, the mother and children live in protected housing.

\section{Conflicts from a life-trajectory and gender perspective}

Circumstances of significance for the understanding of conflicts between parents involved in a custody dispute include the family's living situation, the previous relationship between the parents, the conflicts that took place when they lived together, and relationships with other people in the network (Birnbaum \& Bala, 2010). The analysis shows that $24 \%$ of the cases involve parents who are in the middle of a separation. For $42 \%$ of the parents, one to three years have passed since the separation, whereas $33 \%$ are in the midst of long-term conflicts in which four years or more have passed since the separation. This result corresponds with previous research and governmental inquiries (Rejmer, Bergman, Piasecka, Rydén, \& Varis, 2017; SOU, 2017:6). Many parents involved in long-term conflicts have previously pursued custody disputes in the courts. Their children have been investigated by social services after reports of concern. For a number of parents in long-standing conflicts, an image of complex psychosocial problems becomes apparent, with elements of mental illness, addiction, financial problems, and housing problems. In this group of parents, there are also people with experience of being a refugee.

Upon separation, the families have generally been those with small children. It is common for the parents to have built their family quickly; they met, moved in together, had children, and separated over a maximum period of four years. This applies to parents in approximately a quarter of the cases. Many parents describe how their relationships were filled with conflict even when they were together. The relationships are described with strong words such as "turbulent" and as an "on-off" relationship. In many cases, the separations have been described as troublesome. There are accounts of how one parent has left home, disappeared, moved, or that one parent has been "thrown out" by the other. These descriptions illustrate the rapid breakups and abrupt separations that can lead to a difficult crisis (Ahrons, 2011). There are also examples of where infidelity was a deciding factor in the separation. In other cases, deciding factors such as violence and/or threats are reported. There are further examples that the conflict between the parents has deteriorated when a new partner has arrived on the scene or when one parent relocates, causing practical cooperation difficulties due to geographical distances.

A gender perspective can be established to highlight the conflicts between the parents on a societal level. The results indicate that society's equality endeavors have made a breakthrough in custody disputes. The division of women and men applying for summonses for custody, residence and access falls within the Swedish political definition of gender equality, $60 / 40 \%$ 
(Govt. Bill, 1978/79:175). Gender equality means equal power, the same opportunities, rights, and obligations for woman and men. In Sweden there is a quantitative aspect of equality. If a group comprises more than $60 \%$, it is considered to be dominated by one gender (Statistics Sweden, 2016). In the cases examined, the mothers are behind $58 \%$ of the summonses and the fathers, $42 \%$. There are gender differences. A greater number of mothers than fathers request for sole custody and for the child's access with the father to be reduced or discontinued. Fathers also request for sole custody, but there are also those who request for joint custody and alternating residence, which requires close collaboration between the parents. In respect of child access, fathers request for scheduled access or for the child to have increased access with him. Consequently, mothers appear to request for a reduction in the fathers' participation and influence in the child's life, whereas fathers request for participation and influence and for more involvement in their children's lives.

\section{Discussion}

The article examines parental disputes in matters of custody, residence, and access for the joint children, and aims to understand the conflicts that form the basis of the disputes. The results show that there are gender differences. More mothers than fathers request for sole custody. More fathers request for joint custody and alternating residence. One interpretation is that the fathers want increased participation in their children's lives as many children live with their mothers. In other words, the results indicate that there is an inverted social gender order in custody disputes, in which the mothers have more control over the situation as the child more often lives with them. However, one explanation for a number of mothers applying for sole custody of their children is that they and/or the children have been subjected to violence from the children's father. These mothers feel powerless in the joint custody situation.

When viewed from a life-trajectory perspective, the families have generally been families with small children at the time of separation. It is common for the parents to have rapidly built the family; they met, moved in together, had children and separated over the course of a maximum of four years. As a result, many parents have undergone several disruptive life-changing events over a short period. Previous research also shows that many parents who develop disputes have built a family relatively quickly (Rejmer, 2003). Divorces during this period in life are a particularly large change for families with small children who are vulnerable (Ahrons, 2011). Some parents have already separated before their joint child is born and, in practice, have never participated in parenthood together. There are also parents who have not experienced a stable relationship together. Thus, they have never developed 
a common family system, nor have they got to know each other in the parental role. This group of parents is one that has increased over time (Statistics Sweden, 2013).

The parents' conflicts are first and foremost conflicts of values. The most common matters involve concerns about the parents' lack of child care ability and cooperation difficulties. It is also common for there to be details of violence, addiction, and poor health among the parents. On many occasions, the conflicts involve the parents' (often the mothers') concerns about the care and safety of the younger children. Cashmore and Parkinson (2011) found similar results in an Australian study, where it was common for parents involved in conflict after separation to be worried about the care and safety of the younger children.

In one-third of the cases, the parents have been involved in long-term conflicts that have been ongoing for more than four years. The children affected have lived with difficult parental conflicts for the greater part of their livessometimes all their life. Long-term parental conflicts can be interpreted as particularly serious when they have been difficult to resolve, despite previous attempts (cf. Saini \& Birnbaum, 2007). Parents can be in conflict at the time of a separation, but for the majority, the conflict level reduces over time. Nevertheless, for some parents, the conflicts continue over a longer period or can even intensify (Kelly \& Emery, 2003). An explanation for this is that the parents' conflicts of values are often based on different interpretations of the presence of addiction, mental illness, violence, and what the child wants, while the custody investigator from the social services simultaneously lacks support from the law to investigate these circumstances without the consent of the parents (Rejmer, 2015). As a result, the parents' accusations against each other often go without investigation, which can lead to an escalation in the conflict. Consequently, there is a need to reform legislation so that custody investigators are provided with the necessary authority to investigate the wishes and the best interest of the individual child. The Swedish parental code was introduced 1950, mirroring traditional family values. Since then new ideas regarding children, parenthood, divorce, and gender have been established in society. The Swedish parental code has continuously undergone minor reforms to adopt the normative changes, but the legislative bodies has not taken into account that the normative changes also changed the nature of the conflict from conflict of interest to conflict of values demanding different interventions from the society.

The analysis of the parental conflicts can be interpreted in such a way that many parents find themselves in a difficult family situation and life adjustment, which has led to a crisis. When combined, various different circumstances-via a cumulative result-have created the grounds upon which a dispute has developed (cf. Rejmer, 2003). There are currently no societal initiatives for parents embroiled in serious conflicts of values and complex problems. The help available in Sweden for parents involved in a 
custody dispute includes meetings with the social services and rulings made by the court. Both of the aforementioned are best suited to helping parents with conflicts of interest. Our study shows that parents involved in custody disputes in particular have a conflict of values and that a number of parents are also socially excluded and have complex problems. Therefore, a development in methodology is needed so that society can offer needs-oriented support to these parents and children.

\section{Funding}

The conduct of this article was funded by The Swedish Research Council (Vetenskapsrådet) and The Public Health Agency of Sweden (Folkhälsomyndigheten).

\section{References}

Ahrons, C. R. (2011). Divorce: An unscheduled family transition. In M. McGouldrick, B. Carter, \& N. Garcia Preto (Eds.), The expanded family life cycle: Individual, family and social perspectives. Chapter 19. Boston, MA: Pearson Allyn \& Bacon.

Aubert, V. (1989). Continuity and development: In law and society. Oslo, Sweden: Norwegian University Press.

Bergström, G., \& Boréus, K. (2005). The meaning and power of the text: methodology in social science text- and discourse analysis. Lund, Sweden: Studentlitteratur.

Birnbaum, R., \& Bala, N. (2010). Toward the differentiation of high-conflict families: An analysis of social science research and Canadian case law. Family Court Review, 48(3), 403-416. doi:10.1111/j.1744-1617.2010.01319.x

Cashmore, J., \& Parkinson, P. (2011). Reasons for disputes in high conflict families. Journal of Family Studies, 17(3), 186-203. doi:10.5172/jfs.2011.17.3.186

Connell, R. (1987). Gender and power: Society, the person and sexual politics. Cambridge, UK: Polity.

Giddens, A., \& Birdsall, K. (2003). Sociologi. Lund, Sweden: Studentlitteratur.

Govt. Bill. (1978/79:175). With a proposal for a law on equality between men and women in working life, etc.

Johansson, T. (2012). Part-time fatherhood - everyday life, masculinity and marginalization. In M. Bäck-Wiklund \& T. Johansson (Eds.), The Network Family. Chapter 4. Stockholm, Sweden: Natur \& Kultur.

Johnston, J. (1994). High-conflict divorce. The Future of Children, 4(1), 165-182. doi:10.2307/ 1602483

Johnston, J., Roseby, V., \& Kuehnle, K. (2009). In the name of the child - A developmental approach to understanding and helping children of conflicted and violent divorce. New York, NY: Springer.

Kelly, J., \& Emery, R. (2003). Children's adjustment following divorce: Risk and resilience perspectives. Family Relations, 52(4), 352-362. doi:10.1111/j.1741-3729.2003.00352.x

Leon, K. (2003). Risk and protective factors in young children's adjustment to parental divorce: A review of the research. Family Relations, 52(3), 258-270. doi:10.1111/j.17413729.2003.00258.x

Rejmer, A. (2003). Custody disputes. A socio-legal study of the role of district courts in handling of custody disputes with the child's best interest as a base (Dissertation). Lund, Lunds University, Sociology of Law Department. 
Rejmer, A. (2015). New ways of handling custody disputes. In Y. Söderström-Göthner (Ed.), Children's rights in custody disputes. Chapter 3. Stockholm, Sweden: Stiftelsen Allmänna Barnhuset.

Rejmer, A., Bergman, A., Piasecka, A., Rydén, K., \& Varis, T. (2017). Parents in child custody disputes: Who are they, what is the conflict about and how do they experience the community's interventions? In press: Uppsala University.

Saini, M., \& Birnbaum, R. (2007). Unraveling the label of "high conflict": What factors really count in separated and divorced families? Oacas Journal, 51(1), 14-20.

Saini, M., Black, T., Lwin, K., Marshall, A., Fallon, B., \& Goodman, D. (2012). Child protection workers' experiences of working with high-conflict separating families. Children and Youth Services Review, 34(7), 1309-1316. doi:10.1016/j.childyouth.2012.03.005

Sandström, G. (2012). Ready, willing and able: The divorce transition in Sweden 1915-1974. Dissertation. Umeå: Umeå University, Department of Historical, Philosophical and Religious Studies.

SOU. (2017:6). See the child: Report of the 2014 Child Custody Inquiry.

Statistics Sweden. (2001). Mothers and fathers: On being a parent. Demographic reports 2002:7.

Statistics Sweden. (2013). Children, parents and separations: Trends of the 21st Century. Demographic reports 2013:1.

Statistics Sweden. (2014). Different families live in different ways - a survey on residence and support of children after a separation. Demographic reports 2014:1.

Statistics Sweden. (2016). Woman and men in Sweden: Facts and figures 2016.

Stewart, J. W. (2000). Symptoms of emotional damage to children of high-conflict divorce in the child custody book: How to protect your children and win your case. Atascadero, CA: Impact.

Swedish National Board of Health \& Welfare. (2011). Social services and child in custody disputes: A follow-up of the effects of the 2006 reform of the Children and Parents Code.

Swedish National Courts Administration. (2003). Court statistics.

Swedish National Courts Administration. (2009). Court statistics.

Swedish National Courts Administration. (2013). Court statistics. 